\title{
System levelized fuel cost of electricity generation in a two-component nuclear energy system with a closed uranium-plutonium NFC $^{*}$
}

\author{
Anatoly V. Zrodnikov ${ }^{1}$, Viktor M. Dekusar ${ }^{1}$, Olga S. Gurskaya ${ }^{1}$ \\ 1 SSC RF-IPPE n.a. A.I. Leipunsky JSC, 1 Bondarenko Sq., 249033 Obninsk, Russia \\ Corresponding author: Viktor M. Dekusar(decouss@ippe.ru)
}

Academic editor: Georgy Tikhomirov • Received 21 June 2021 Accepted 19 October 2021 • Published 17 December 2021

Citation: Zrodnikov AV, Dekusar VM, Gurskaya OS (2021) System levelized fuel cost of electricity generation in a two-component nuclear energy system with a closed uranium-plutonium NFC. Nuclear Energy and Technology 7(4): 303-309. https://doi.org/10.3897/ nucet.7.78367

\begin{abstract}
The authors propose an approach to the calculation of the levelized unit fuel cost (LUFC) of electricity generation for a fast reactor in a two-component nuclear energy system (NES) with regard for plutonium production. The approach is based on taking into account the additional economic effect, which can be achieved through the sale at the market price of the natural uranium released due to the substitution of thermal reactors by fast reactors with MOX fuel based on the plutonium bred in a fast reactor. This requires considering simultaneously the reactor parts of the fuel cycle for fast and thermal reactors. Relationships have been obtained which connect the key neutronic and fuel characteristics with the NPP and fuel cycle economic performance. The described methodology was used for the computational study of the $L U F C$ for a fast sodium-cooled reactor. Calculations have shown that, in the considered case, taking into account the plutonium production leads to the $L U F C$ reduction by nearly half and, therefore, to a major decrease in the total unit cost of electricity generation (levelized cost of electricity or $L C O E$ ).
\end{abstract}

\section{Keywords}

nuclear fuel cycle closure, technical and economic performance, plutonium production, levelized unit fuel cost, additional income, fast and thermal reactors

\section{Introduction}

Closing the nuclear fuel cycle solves the problem of using in a nuclear power system (NES) a second (in addition to energy) product, i.e., secondary nuclear materials recovered from spent nuclear fuel (SNF). Of the greatest interest among them is plutonium as an additional resource in nuclear power engineering at present. After the depletion of economically affordable natural uranium reserves, plu- tonium should become the main resource for the further development of the NES. While electric or thermal energy currently has an explicit consumer and is paid for accordingly, the associated plutonium production does not yet have a cash equivalent. At the same time, the costs of plutonium production are actually included in the levelized unit fuel cost (LUFC) of electricity generation, which leads to a deformation of the economic indicators of nuclear power plants. However, it is practically impossible

* Russian text published: Izvestiya vuzov. Yadernaya Energetika (ISSN 0204-3327), 2021, n. 3, pp. 5-17.

Copyright Zrodnikov AV et al. This is an open access article distributed under the terms of the Creative Commons Attribution License (CC-BY 4.0), which permits unrestricted use, distribution, and reproduction in any medium, provided the original author and source are credited. 
to separate the costs of electricity generation and plutonium production, which always occurs when irradiating uranium-based nuclear fuel. As a result, the traditional comparative technical and economic analysis can lead to an erroneous choice of the trajectory for the further development of nuclear power engineering.

One of the possible criteria for accounting for plutonium production may be a modified $L U F C$ with due consideration of the additional benefit obtained from the use of the produced plutonium as a commodity. However, the absence of a market for plutonium, due to its specific characteristics, does not allow the indicated benefit to be determined. Under these conditions, there is no question of the price of plutonium - money for which the sellers are ready to transfer their goods (in this case, plutonium) to the buyers. Apparently, it can be stated that this situation, due to the specifics of the product, will persist in the foreseeable future.

At the same time, like any manufactured product, plutonium has its own cost, which, on the one hand, must cover the costs of the manufacturer for its production. On the other hand, plutonium, being an efficient energy carrier, due to its neutronic properties, makes it possible to carry out expanded reproduction of nuclear fuel in the fast neutron spectrum. Thus, plutonium-fueled fast reactor technology may actually become a renewable energy source, which is a prerequisite for the development of nuclear power in any foreseeable future.

The developed approach to determining the $L U F C$ makes it possible in fact to reduce to a single complex criterion expressed in monetary form, i.e., $L U F C$, a set of basic parameters describing the physical characteristics and economic indicators of reactors and nuclear energy systems as a whole, which are of a very heterogeneous nature. The proposed criterion may turn out to be useful in performing a systemic multicriteria analysis of a nuclear power system (Egorov et al. 2017, Alekseev et al. 2020), comparing its technical and economic indicators with reactors of various types, and choosing the ways of developing nuclear power engineering.

This approach has been formulated for the first time.

\section{Traditional approach to calculating the LUFC of electricity production at nuclear power plants}

Let us recall the main provisions of the traditional approach to calculating the LUFC (OECD/NEA 1994, IAEA 2008, IAEA 2014, Dekusar et al. 2014, Chernyakhovskaya 2016).

Traditionally, the $L U F C$ is the average value of fuel costs per $1 \mathrm{kWh}$ of electricity generated over the entire service life of a nuclear power plant. Since the costs associated with fuel are incurred throughout its life cycle, covering a period of up to 100 years or more, the method of reduced costs is used to take into account the disparity in monetary costs (OECD/NEA 1994, IAEA 2008, IAEA 2014); this actually takes into account the value of money.

Equalization of the reduced income and fuel cycle costs makes it possible to determine the constant reduced specific fuel cost or, in the terminology of works (IAEA 2008, IAEA 2014), the LUFC (Levelized Unit Fuel Cost):

$$
L U F C=\frac{\sum_{\text {stagestime }} \sum F_{i}(t) /(1+r)^{\left(t-t_{0}\right)}}{\sum_{\text {time }} E(t) /(1+r)^{\left(t-t_{0}\right)}}
$$

The above ratio for calculating the $L U F C$ refers to a single-product model, which takes into account only one source of income, i.e., the sale of electricity.

\section{Economic effect of plutonium production in a nuclear energy system}

Let us consider the possibility of taking into account the production of plutonium in an analysis of cash and fuel flows and cost indicators of a NES, as was done in (Dekusar and Gurskaya 2021) when considering the price of plutonium. It is assumed that the NES includes NPPs with thermal and fast reactors and the infrastructure of a closed nuclear fuel cycle. Commissioning a fast reactor of equivalent power instead of a thermal VVER-type reactor makes it possible to save about 200 tons of natural uranium annually, which provides the possibility of generating additional income.

The additional income can be determined through the market price of the saved natural uranium. This income can also be obtained by selling the corresponding quantities of enriched uranium or fuel assemblies for thermal reactors, etc., manufactured on the basis of this uranium.

Since the release of uranium takes place throughout the entire life cycle of a nuclear power plant, the additional income should be reduced (discounted) to a specific date in the same way as it is done when fuel costs are determined (OECD/NEA 1994, IAEA 2008, Dekusar et al. 2014, Chernyakhovskaya 2016).

The ratio for the discounted income $E_{\text {add }}$ received for the entire design service life of a power unit of duration $L$ for the case of natural uranium can be written as

$$
E_{\text {add }}=\sum_{t=t_{0}+\Delta t}^{t_{0}+L+\Delta t} \frac{C_{\mathrm{U}}\left(1+e S_{\text {add }}\right)^{\left(t-t_{0}\right)} \Delta G^{\mathrm{U}}(t)}{(1+r)^{\left(t-t_{0}\right)}}
$$

where $E_{\text {add }}$ is the is the required additional income obtained by saving natural uranium; $t_{0}$ is the base date (usually this is the moment when the reactor is commissioned); $L$ is the is the duration of the NPP life cycle; $r$ is the discount rate; $C_{\mathrm{U}}$ is the unit cost of products entering the market (in this case, it is natural uranium), due to which additional income is provided, $\$ / \mathrm{kg}$; $e s_{\text {add }}$ is the annual escalation of 
the unit price of products offered for sale (can be positive, negative or zero); $\Delta G^{\mathrm{U}}$ is the mass of products (natural uranium) that can be supplied to the market annually when thermal reactors are replaced with fast ones; $\Delta t$ is the time lag (delay or advance interval) between the time of receipt of income from the sale of released uranium (or fuel assemblies) and the base date.

To simplify the further presentation, we will assume that $\Delta G^{\mathrm{U}}(t)$ in formula (2) is a continuous function, and the discount rate $r$ is constant. Let us make a similar assumption for all the other summable time functions considered in the paper. Then the sum in (2) can be replaced by an integral with simultaneous replacement of power exponents by exponents in accordance with relations of the form $1 /(1+r)^{t}=\exp \left(-\lambda_{d} t\right)$ and the expression for the income discounted by the time $t_{0}$ can be written as

$$
\begin{gathered}
E_{\text {add }}=\int_{t_{0}+\Delta t}^{t_{0}+L+\Delta t} C_{\mathrm{U}} \Delta G^{\mathrm{U}}(t) \exp \left(-\left(\lambda_{d}-\lambda_{\mathrm{es}}\right)\left(t-t_{0}\right)\right) d t \\
\lambda_{d}=\ln (1+\mathrm{r}), \lambda_{e s}=\ln \left(1+e s_{\text {add }}\right) .
\end{gathered}
$$

The obvious (guaranteed) possibility of saving uranium occurs after loading the fuel made on the basis of separated plutonium into the reactor, i.e. at the same time, it is implicitly assumed that the "unsold" plutonium will be replaced by completely marketable uranium. This usually takes place several years after the corresponding SNF batch has been unloaded from the reactor. Consequently, in this case, the value of $\Delta t$ is positive and ranges, as a rule, between five and seven years.

It is possible to earn income from the sale of saved uranium even before the corresponding equivalent is obtained in the form of separated plutonium. Moreover, in principle, this can be done even before the commissioning of a nuclear power plant with a fast reactor. This simply requires a stock of uranium in storage. In these cases, the value of $t$ is negative, and its absolute value can be within fairly wide limits. The value of $\Delta t$ can also be zero, which corresponds to the simultaneity of the start of generating income from the sale of electricity and the sale of saved uranium.

\section{Calculation model for a system of thermal and fast reactors}

The amount of released natural uranium and the corresponding economic benefit, when thermal reactors are replaced with fast ones, can be determined as a result of mathematical modeling of a specific NES. The result obtained in this case is of a purely private nature, relating only to this NES. At the same time, the most interesting are models that claim to be somewhat versatile.

For this purpose, we shall consider the simplest mathematical model of a NES with a growing installed power. Let us assume that the power generating part of this NES includes only fast reactors of the same type with constant characteristics, operating on mixed uranium-plutonium fuel. Fast reactors are characterized by the secondary plutonium storage coefficient $(S C)$, which is understood as the ratio of the annual unloading of plutonium from a fast reactor to its annual loading. It is assumed that the system has an equilibrium isotopic composition of plutonium.

We will assume that the increase in the installed capacity of fast reactors in the NES is determined only by the capabilities of the system for the production of plutonium. In this case, additional income is understood as the saved costs that would be incurred by the NES in its development with the achievement of the same power level, but using only thermal reactors and without commissioning fast reactors.

Consider the equations describing the state of the system in time by the number of fast reactors. In this case, we will proceed from the concept of a system of reactors (Walter and Reynolds 1986), in which all the excess plutonium produced is spent on the commissioning of new reactors.

The amount of plutonium required to launch one fast reactor with the condition of filling its external fuel cycle is calculated as follows

$$
G_{\mathrm{Pu}}=G_{\mathrm{Pu}}^{0}+T_{\mathrm{ext}} \frac{G_{\mathrm{Pu}}^{0}}{T},
$$

where $G_{\mathrm{Pu}}{ }^{0}$ is the initial plutonium loading of the fast reactor, $\mathrm{t} ; T$ is the duration of the fast reactor fuel assembly campaign, years; $T_{\text {ext }}$ is the duration of the external fuel cycle, years.

The annual excess plutonium from $N_{\mathrm{FR}}(t)$ of fast reactors will be

$$
N_{\mathrm{FR}}(t) \frac{G_{\mathrm{Pu}}^{0}}{T}(K H-1)(1-\varepsilon)
$$

where $\varepsilon$ is the loss of plutonium in the fuel cycle.

Then the rate of change in the number of fast reactors is described by the differential equation

$$
\frac{d N_{\mathrm{FR}}(t)}{d t}=N_{\mathrm{FR}}(t) \frac{(S C-1)(1-\varepsilon)}{T+T_{\mathrm{ext}}}
$$

with the initial condition $N_{\mathrm{FR}}(0)=N_{\mathrm{FR}}{ }^{0}$.

We will denote

$$
\lambda_{2}=(S C-1)(1-\varepsilon) /\left(T+T_{\text {ext }}\right)
$$

$\lambda_{2}$ is related to the period of doubling the power $T_{2}$ in the system of fast reactors by the ratio

$$
\lambda_{2}=\ln 2 / T_{2} .
$$

Then equation (7) can be represented by the expression

$$
\frac{d N_{\mathrm{FR}}(t)}{d t}=\lambda_{2} N_{\mathrm{FR}}(t)
$$

which is solved as follows

$$
N_{\mathrm{FR}}(t)=N_{\mathrm{FR}}^{0} \exp \left(\lambda_{2}\left(t-t_{0}\right)\right) .
$$




\section{Calculation of potential additional income from economy of natural uranium}

To determine additional income, we will use formula (3). In this formula, the amount of released natural uranium is determined from the ratio

$\Delta G^{\mathrm{U}}(t)=G_{\mathrm{TR}}^{\mathrm{U}} N_{\mathrm{TR}}(t)=G_{\mathrm{TR}}^{\mathrm{U}} x N_{\mathrm{FR}}(t)=G_{\mathrm{TR}}^{\mathrm{U}} x N_{\mathrm{FR}}^{0} \exp \left(\lambda_{2}\left(t-t_{0}\right)\right)$,

in which the number of thermal reactors is determined from the condition of equality of power generation at thermal reactors and introduced fast reactors at any time interval

$$
N_{\mathrm{TR}}(t) P_{\mathrm{TR}} \times I C U F_{\mathrm{TR}}=N_{\mathrm{FR}}(t) P_{\mathrm{FR}} \times I C U F_{\mathrm{FR}}
$$

The number of introduced fast reactors depends on the amount of produced plutonium and is determined by formula (11).

In formula (12) $x=\left(P_{\mathrm{FR}} \times I C U F_{\mathrm{FR}}\right) /\left(P_{\mathrm{TR}} \times I C U F_{\mathrm{TR}}\right) ; P$ and $I C U F$ are the installed capacity and its utilization factor for a thermal reactor (TR) or fast reactor (FR), respectively; $N_{\mathrm{FR}}{ }^{0}$ is the number of fast reactors at time $t=t_{0} ; G_{\mathrm{TP}}^{\mathrm{U}}$ is the annual demand of TR in natural uranium, $\mathrm{kg}$.

After performing the integration in (3), we obtain the following formula for determining the additional income:

$$
E_{\mathrm{add}}=C_{\mathrm{U}} G_{\mathrm{TR}}^{\mathrm{U}} x N_{\mathrm{FR}}^{0} F(\lambda) .
$$

In formula (13), the function $F(\lambda)$, is introduced, which in general form defined by the relation

$$
F(\lambda)=\frac{\exp (\lambda \Delta t)}{\lambda}(\exp (\lambda L)-1)
$$

where $\lambda=\lambda_{2}-\lambda_{d}+\lambda_{e s}$, and $\lambda_{d}$ and $\lambda_{e s}$ are defined by relation (4).

\section{The levelized unit fuel cost taking into account plutonium production in fast reactors}

The $L U F C$ of electricity production, taking into account the production of plutonium, will be determined in the same way as it is done in the traditional approach when the reduced costs and reduced income are equalized. However, in contrast to the traditional approach, in the reduced income, in addition to the income from the sale of electricity, we will include the income from the production of plutonium.

Then the $L U F C$, taking into account the production of plutonium, will be determined from the following expression:

$\sum_{i} \sum_{t=t_{0}-T_{\mathrm{T}}}^{t=t_{0}+T_{\text {ead }}} F_{i}(t) /(1+r)^{\left(t-t_{0}\right)}=\sum_{t=t_{0}}^{t=t_{0}+L} \frac{L U F C \cdot E(t)}{(1+r)^{\left(t-t_{0}\right)}}+\sum_{t=t_{0}+\Delta t}^{t=t_{t}+\Delta t+L} \frac{C_{\mathrm{U}}\left(1+e S_{\text {add }}\right)^{\left(t-t_{0}\right)} G_{\mathrm{U}}(t)}{(1+r)^{\left(t-t_{0}\right)}}$
The notations here are the same as in the previous formulas.

From here, we can obtain the following relation for the LUFC

$L U F C=\frac{\sum_{i} \sum_{t=t_{0}-T_{t}}^{t=t_{0}+L+T_{\text {oud }}} F_{i}(t) /(1+r)^{\left(t-t_{0}\right)}}{\sum_{t=t_{0}}^{t=L} E(t) /(1+r)^{\left(t-t_{0}\right)}}-\frac{C_{U} \sum_{t=t_{0}+\Delta t}^{t=t_{0}+L+\Delta t}\left(1+e S_{\text {add }}\right)^{\left(t-t_{0}\right)} G_{\mathrm{U}}(t) /(1+r)^{\left(t-t_{0}\right)}}{\sum_{t=t_{0}}^{t=L+L} E(t) /(1+r)^{\left(t-t_{0}\right)}}$

The first term on the right in expression (15) represents the fuel component in the one-product model (production of electricity only); let us denote it as $L U F C_{0}$.

Then expression (15) can be rewritten as

$$
L U F C=L U F C_{0}-\frac{C_{U} \sum_{t=t_{0}+\Delta t}^{t=t_{0}+L+\Delta t}\left(1+e S_{\text {add }}\right)^{\left(t-t_{0}\right)} G_{\mathrm{U}}(t) /(1+r)^{\left(t-t_{0}\right)}}{\sum_{t=t_{0}}^{t=t_{0}+L} E(t) /(1+r)^{\left(t-t_{0}\right)}}
$$

or

$$
L U F C=L U F C_{0}-\triangle(L U F C) .
$$

The value of $\triangle(L U F C)$ is an additional income per 1 $\mathrm{kWh}$ of electricity generated in the system due to the refusal to use natural uranium in thermal reactors when they are replaced by fast ones. The same value can be interpreted as compensation under these conditions for the fuel consumption of fast reactors.

Passing from summation to integration over time and making the necessary transformations, we obtain

$$
\Delta(L U F C)=\frac{C_{\mathrm{U}} G_{\mathrm{TR}}^{\mathrm{U}}}{P_{\mathrm{TR}} I C U F_{\mathrm{TR}} 8766} f
$$

where 8766 is the average number of hours per year; $f$ is the dimensionless function of variables characterizing the reactor and the fuel cycle:

$$
f=\frac{\lambda_{d 2} \exp (\lambda \Delta t)(\exp (\lambda L)-1)}{\lambda\left(\exp \left(\lambda_{d 2} L\right)-1\right)}
$$

where $\lambda_{d 2}=\lambda_{2}-\lambda_{d}$.

Function $f$ can be called the relative economic efficiency of using plutonium in a NES with thermal and fast reactors in a closed fuel cycle. The greater the value of this function in a particular case, the more efficiently plutonium is used in a given NES, and thus fuel costs can be reduced (compensated) in it. Formula (18) shows the limiting relative efficiency that can be achieved in accordance with the considered NES model.

Among the variables on which the $L U F C$ generally depends are the variables responsible for both the economic performance and the neutronic characteristics of the reactor and the fuel cycle. The economic indicators include the discount rate, the escalation of the price of natural uranium and the time lag between the time the product enters the market and the time the power unit is commissioned.

The $T_{2}$ value (the time of doubling the installed capacity of the fast reactor system) is responsible for the reactor and the fuel cycle. It is determined by the plutonium storage coefficient, the duration of the fuel campaign in the reactor, and the duration of the external fuel cycle. 
The latter mainly depends on the technological features of the fuel cycle and the radiation characteristics of the irradiated fuel.

\section{The $L U F C$ of a high-power fast sodium reactor, taking into account the production of plutonium}

Let us consider the application of the described method for calculating the $L U F C$ through the example of a power unit with a high-power fast sodium reactor.

The calculations are based mainly on the physical and technical characteristics of a high-power power unit, adopted in accordance with (OECD/NEA 1994, Poplavsky et al. 2010, Matveev and Khomyakov 2012, Alekseev et al. 2016).

The following time intervals are accepted: after unloading from the reactor, the SNF is kept for two years in the in-reactor storage, then for one year in the spent fuel pool, and for another year the SNF is reprocessed, fresh fuel is produced and transported. Thus, the duration of the external fuel cycle is assumed to be four years.

The data on fuel loads and unit costs for redistribution of the nuclear fuel cycle were taken from (Bunn et al. 2003, Deutch et al. 2003, Shropshire et al. 2008, Alekseev et al. 2016). Centralized production of MOX-fuel assemblies and fuel assemblies of the lateral reproduction zone, as well as SNF reprocessing are planned. It should be noted that the unit costs for the fuel cycle redistribution largely determine the value of the $L U F C$, and the cost of manufacturing MOX fuel and reprocessing spent nuclear fuel (taken in the calculations, respectively, $\$ 3500 / \mathrm{kg} \mathrm{tm}$ and $\$ 770 / \mathrm{kg} \mathrm{tm}$ ) are of decisive importance. The price of waste uranium in the calculations was taken to be zero.

The results of calculations of the $L U F C_{0}$ at discount rates $(r) 0,5$ and $10 \%$ excluding plutonium production are given in Table $1\left(1 \mathrm{mills}=10^{-3} \$\right)$.

Table 1. $L U F C_{0}[\mathrm{mills} / \mathrm{kWh}]$ for a high-power fast reactor at discount rates of 0,5 and $10 \%$

\begin{tabular}{lccc}
\hline \multicolumn{1}{c}{ Stages of the fuel cycle } & $\boldsymbol{r}=\mathbf{0} \%$ & $\boldsymbol{r}=\mathbf{5 \%}$ & $\boldsymbol{r}=\mathbf{1 0} \%$ \\
\hline Initial & 6.45 & 7.45 & 8.87 \\
Final & 3.95 & 1.60 & 1.18 \\
Full $L U F C_{0}$ & 10.40 & 9.05 & 10.05 \\
\hline
\end{tabular}

As can be seen from the data in the table, when the discount rate changes from 0 to $10 \%$, the $L U F C_{0}$ first decreases and then slightly increases. The nonmonotonic dependence of the $L U F C_{0}$ as a function of the discount rate $r$ is explained by the multidirectional changes in the contributions to the $L U F C_{0}$ of the initial and final stages of the fuel cycle.

Let us consider the effect of saving natural uranium when a VVER-TOI thermal reactor is replaced with a fast reactor of the same power. The $G_{\mathrm{TP}}^{\mathrm{U}}$ value can be taken equal to 200 tons, which corresponds to approximately 22.5 tons of enriched $\left(4.3 \%\right.$ in $\left.{ }^{235} \mathrm{U}\right)$ uranium per year. The results of calculations of the $L U F C$, as well as additional income for the entire life cycle of a nuclear power plant with a fast reactor, taking into account the production of plutonium in it, are presented in Tab. 2. The calculations were performed using the FCCBNN program (OECD/ NEA 1994). The influence of the discount rate in the range of $0-10 \% / y e a r$ was taken into account. Plutonium losses were assumed to be zero.

Table 2. Technical and economic indicators of a fast reactor of high power, taking into account the market value of the released natural uranium at $T_{2} \rightarrow \infty$

\begin{tabular}{|c|c|c|c|c|c|c|c|}
\hline \multirow{2}{*}{$\begin{array}{c}\text { Uranium } \\
\text { price, \$/ } \\
\text { kg }\end{array}$} & \multirow{2}{*}{$\begin{array}{c}\Delta(\text { LUFC }) \\
\text { mills/ } \\
\text { kWh }\end{array}$} & \multicolumn{3}{|c|}{$L U F C$, mills/kWh } & \multicolumn{3}{|c|}{ Additional income, B\$ } \\
\hline & & $r=0 \%$ & $r=5 \%$ & $r=10 \%$ & $r=0 \%$ & $r=5 \%$ & $r=10 \%$ \\
\hline 50 & 1.04 & 9.36 & 8.01 & 9.01 & 0.60 & 0.20 & 0.11 \\
\hline 100 & 2.07 & 8.33 & 6.98 & 7.98 & 1.20 & 0.39 & 0.21 \\
\hline 150 & 3.10 & 7.30 & 5.95 & 6.95 & 1.80 & 0.58 & 0.31 \\
\hline 200 & 4.14 & 6.26 & 4.91 & 5.91 & 2.40 & 0.78 & 0.42 \\
\hline 250 & 5.18 & 5.22 & 3.87 & 4.87 & 3.00 & 0.97 & 0.52 \\
\hline 300 & 6.21 & 4.19 & 2.84 & 3.84 & 3.60 & 1.16 & 0.63 \\
\hline
\end{tabular}

As can be seen from the presented results, the production of plutonium makes it possible to obtain serious additional income (from 0.11 to $3.6 \mathrm{~B} \$$ depending on the price of natural uranium and the discount rate) by selling the saved natural uranium on the market. Accounting for this income in an equivalent way leads to a noticeable decrease in the LUFC. Comparison of the data in Tab. 1 (line "full $L U F C_{0}$ ") and 2 shows that at a price of natural uranium equal to $\$ 50 / \mathrm{kg}$, taking into account the production of plutonium reduces the $L U F C$ by about $10 \%$. If the cost of natural uranium increases to $\$ 300 / \mathrm{kg}$, which is quite possible on the horizon of the current century, with the intensive development of nuclear power engineering with thermal reactors, the $L U F C$ decreases already by two or three times.

Figure 1 shows the results of calculating the $L U F C$ of a fast reactor with the combined account of the closure of the fuel cycle and the escalation of the price of natural uranium. The calculations were carried out for the case of the initial price of released natural uranium at $100 \$ / \mathrm{kg}$ with a possible escalation of $3-5 \%$ per annum. Note that the doubling time in the fuel cycle varied from 10 to 50 years. The $\Delta t$ value was taken to be zero. The figure also shows the $L U F C_{0}$ values.

At non-zero values of the escalation, a rather strong dependence of the $L U F C$ on the doubling time is observed, especially at low values of $T_{2}$.

Figure 2 shows the $L U F C$ values, taking into account the production of plutonium, depending on its storage coefficient with an escalation of the price of natural uranium of 3\%; for clarity, the LUFC data are given at zero escalation (the value is the same at any discount rate and is equal to $8.3 \mathrm{mills} / \mathrm{kWh}$ ). With the $S C=1.17$, which is the case for the standard configuration of a high-power fast sodium reactor, the $L U F C$ will be 4-7 mills/kWh, depending on the discount rate. With an increase in the $S C$ to values of the order of 1.4 , the $L U F C$ will decrease to 3-7 mills/kWh. 

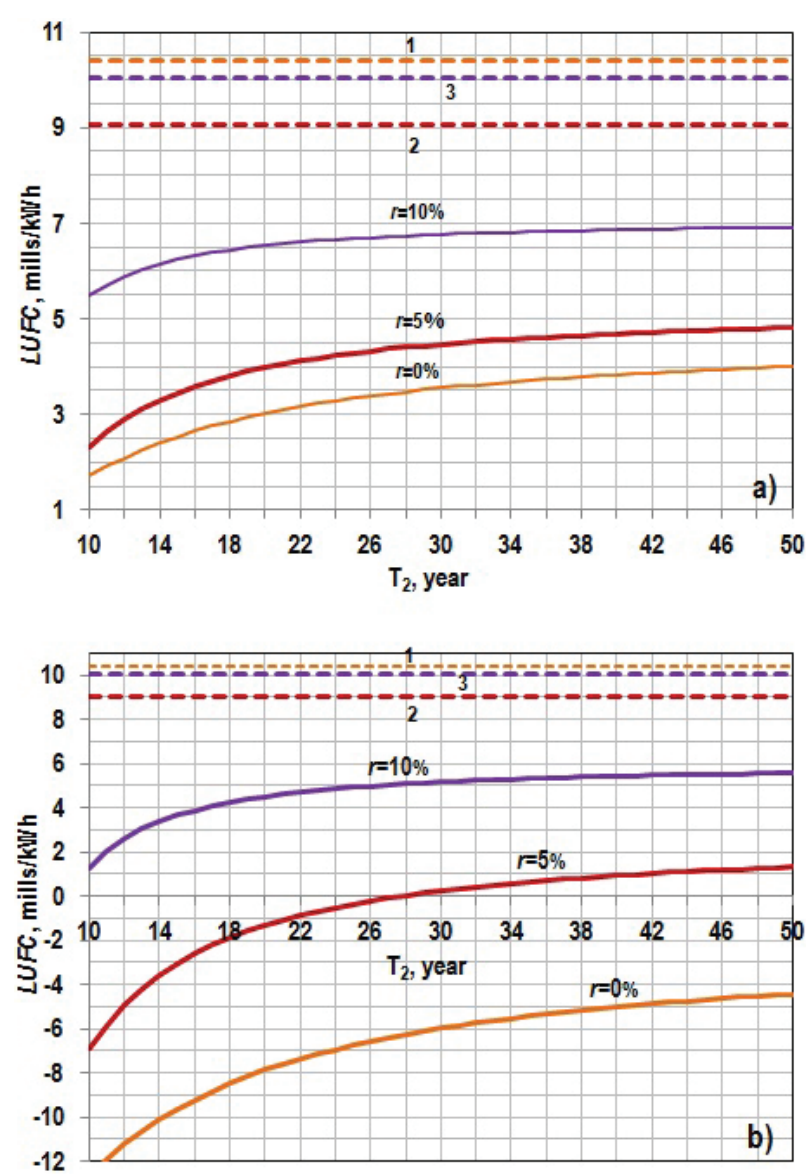

Figure 1. The $L U F C$ of a high-power fast reactor at various discount rates depending on the doubling time with the escalation of the price of natural uranium: a) $-3 \%$; b) $-5 \% .1-L U F C_{0}(r$ $=0 \%) ; 2-\operatorname{LUFC}_{0}(r=5 \%) ; 3-L U F C_{0}(r=10 \%)$.

With an escalation of the price of natural uranium by $5 \%$, the calculations show that the picture does not change qualitatively, but the $L U F C$ values become negative: at $r$ $=0 \%$ for any $S C$; at $r=5 \%$ for $S C>1.43$.

The performed computational studies show that for a power unit with a fast sodium reactor and a fuel cycle with a doubling time of about 50 years, a discount rate of $5 \%$ and at an initial price of natural uranium of $\$ 100 /$ $\mathrm{kg}$ and its annual escalation of $3 \%$ with zero $\Delta t$ (without lagging or advancing), taking into account the production of plutonium leads to an almost two-fold decrease in the $L U F C$, i.e., from 9.0 to $4.8 \mathrm{mills} / \mathrm{kWh}$.

Taking into account that the contribution of $L U F C$ to the levelized cost of electricity (LCOE (OECD 2018 NEA No. 7928)) is about $15 \%$, accounting for plutonium production at NPPs with fast reactors leads to a significant decrease in the $L C O E$, i.e., up to $10 \%$ or more at higher prices for natural uranium. This effect is ultimately due to taking into account the market value of the released uranium in case of its potential export. This effect turns out to be the minimum possible; a greater effect can be achieved when the export of fuel assemblies of thermal reactors manufactured on its basis is accounted for as a high-tech product with the maximum added value.

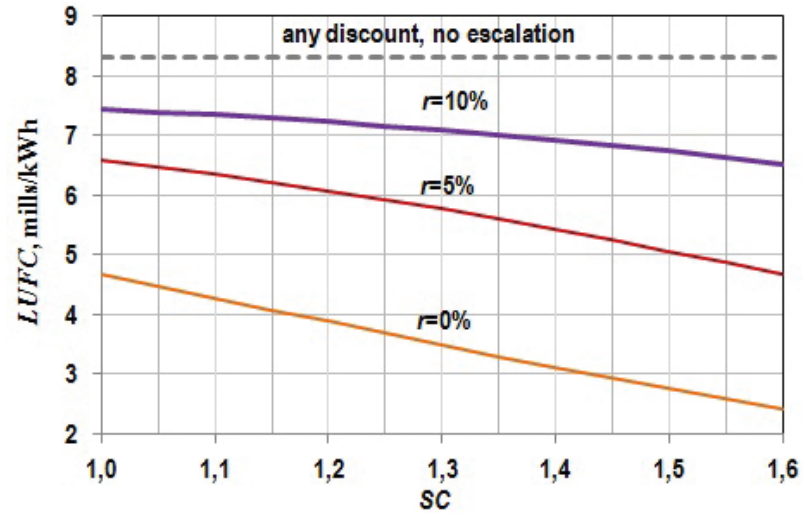

Figure 2. The $L U F C$ for a high-power fast-neutron reactor depending on the storage coefficient with a $3 \%$ escalation of the cost of natural uranium.

\section{Conclusion}

The authors propose an approach to determining the Levelized Unit Fuel Cost (LUFC) for electricity produced in a nuclear energy system by fast and thermal reactors. In contrast to most of the approaches, in this work, an attempt is made to develop a calculation method that takes into account the two-product nature of the technology, i.e., the production of electricity and plutonium. This requires considering simultaneously the reactor parts of the fuel cycle for fast and thermal reactors.

At the same time, the additional income from the production of plutonium in fast reactors is estimated at the cost of saved natural uranium while the fleet of thermal reactors using this uranium is reduced, being replaced with fast reactors using plutonium fuel. The saved uranium has a real market price and can be sold on the market. The proposed approach is based on the energy value of the produced plutonium and thus eliminates the expensive mechanism for assessing its cost. On the basis of these assumptions, a mathematical model was constructed and relations for calculating the $L U F C$ were obtained, linking the main fuel characteristics of the nuclear reactors under consideration and the technical and economic indicators of the fuel cycle of the NES.

The analysis of the obtained relations showed that the $L U F C$ refined in this way depends on many characteristics of the NES. In particular, it is largely determined by the current price of natural uranium and its escalation, the plutonium storage coefficient in a fast reactor, the duration of the external fuel cycle, the plutonium doubling period in the system, etc.

As an example, a computational study of the $L U F C$ in a two-product model of a NES with high-power fast sodium reactors and thermal VVER-type reactors was carried out. The results show that for a power unit with a fast reactor and its fuel cycle with really achievable parameters (doubling time of about 50 years, a discount rate of $5 \%$, an initial price of natural uranium of $\$ 100 / \mathrm{kg}$ and its annual escalation of $3 \%$ ), accounting for plutonium production leads to a decrease in the LUFC from 9.0 to 
4.8 mills $/ \mathrm{kWh}$. Taking into account that the contribution of the $L U F C$ to the levelized cost of electricity ( $L C O E)$ is about $15 \%$, we find that plutonium production leads to a significant decrease in the $L C O E$, i.e., up to $10 \%$ or more.

The technique can be useful for comparative analytical studies to justify the choice of a strategy for the development of a two-component NES with thermal and fast reactors in a single closed NFC.

A characteristic feature of the proposed technique is that the recipients of income from the saved uranium are structures that are sufficiently removed from NPPs (up to the level of a state as a whole). However, there is no doubt about the role of a nuclear power plant with a fast reactor in creating this possibility. It is at NPPs, as a result of nuclear physical processes, that weakly fissionable ${ }^{238} \mathrm{U}$ is converted into an additional raw energy resource, i.e., plutonium. The developed technique makes it possible to see and take into account this income in the technical and economic indicators of a nuclear power plant.

\section{References}

- Alekseev PN, Alekseev SV, Andrianova EA, Asmolov VG, Dekusar VM, Zrodnikov AV, Kagramanyan VS, Koltun OV, Pavlov AS, Ponomarev-Stepnoy NN, Subbotin SA, Temishev PP, Teplov PS, Usanov VI, Tsybulsky VF (2016) Two-Component Nuclear Power System with Thermal and Fast Reactors in the Closed Nuclear Fue Cycle. Tekhnosfera Publ., Moscow, 160 pp. [ISBN 978-5-94836434-6] [in Russian]

- Alekseev PN, Blandinsky VYu, Balanin AL, Grol AV, Nevinitsa VA, Teplov PS, Fomichenko PA, Gulevich AV, Dekusar VM, Egorov AF, Korobeinikov VV, Moseev AL, Marova EV, Maslov AM, Farakshin MR, Shepelev SF, Shirokov AV (2020) Evaluation of the scenarios effectiveness of Russian nuclear power development using multi-criteria analysis. Atomnaya Energiya 128(1): 3-6. [in Russian] https:// doi.org/10.1007/s10512-020-00641-3

- Bunn M, Fetter S, Holdren JP, Zwaan B (2003) The Economics of Reprocessing vs. Direct Disposal of Spent Nuclear Fuel. DE-FG2699FT4028. Cambridge, Mass.: Project on Managing the Atom, Harvard University. https://www.belfercenter.org/sites/default/files/ legacy/files/repro-report.pdf [accessed Jun. 13, 2021]

- Chernyakhovskaya YuV (2016) Evolution of Methodological Approaches to the Assessment of the Cost of Electricity. The Analysis of Foreign Experience. Vestnik IGEU 4: 56-68. [in Russian] https:// doi.org/10.17588/2072-2672.2016.4.056-068

- Dekusar VM, Gurskaya OS (2021) On the issue of plutonium cost in a two-component nuclear power system. VANT. Ser. Yaderno-Reaktornye Konstanty 2: 25-33. [in Russian]

- Dekusar VM, Kolesnikova MS, Chizhikova ZN (2014) Methodology and software for calculation of the fuel component cost of electricity production at nuclear power plants with thermal and fast reactors. Preprint FEI-3243, Obninsk, GNTs RE-FEI, 22 pp. [in Russian]

- Deutch J, Driscoll EM, Gray PE, Holdren JP, Joscow PL, Lester RK, Moniz EJ, Todreas NE (2003) The Future of Nuclear Power: An Interdisciplinary MIT Study. Massachusetts Institute of Technology,
Belfer Center for Science and International Affairs Science, Technology and Public Policy Program. http://www.web.mit.edu/nuclearpower [accessed Jun. 13, 2021]

- Egorov AF, Klinov DA, Korobeinikov VV, Moseev AL, Marova EV, Shepelev SF (2017) Results of multi-criteria analysis of nuclear energy development scenarios in Russia including total energy mix in the state. VANT. Ser. Yaderno-Reaktornye Konstanyy 4: 64-78. [in Russian]

- IAEA (2008) Guidance for the Application of an Assessment Methodology for Innovative Nuclear Energy Systems, INPRO Manual - Economics, Volume 2 of the Final Report of Phase 1 of the International Project on Innovative Nuclear Reactors and Fuel Cycles (INPRO), IAEA-TECDOC-1575/Rev.1, IAEA, Vienna.

- IAEA (2014) INPRO Methodology for Sustainability Assessment of Nuclear Energy Systems: Economics, INPRO Manual, IAEA Nuclear Energy Series No. NG-T-4.4, IAEA, Vienna.

- Matveev VI, Khomyakov YuS (2012) Technical Physic of Sodium Fast Reactors. MEI Publ., Moscow, 355 pp. [in Russian]

- OECD (2018) OECD 2018 NEA No. 7928. The Full Costs of Electricity Provision.

- OECD/NEA (1994) OECD/NEA, The Economics of the Nuclear Fuel Cycle. Paris - 1994. https://www.oecd-nea.org/ndd/reports/efc/ EFC-complete.pdf [accessed Jun. 13, 2021]

- Poplavsky VM, Tsibulya AM, Khomyakov YuS, Matveev VI, Yeliseev VA, Tsikunov AG, Vasil'ev BA, Belov SB, Farakshin MR (2010) Core and fuel cycle for an advanced sodium-cooled fast reactor. Atomnaya Energiya 108(4): 206-211. [in Russian] https://doi. org/10.1007/s10512-010-9287-y

- Shropshire DE, Williams KA, Boore WB, Smith JD, Dixon BW, Dunzik-Gougar M, Adams RD, Gombert D, Schneider E (2008) Advanced Fuel Cycle Cost Basis, INL/EXT-07-12107 Rev.1. https:// core.ac.uk/download/pdf/71325086.pdf [accessed Jun. 13, 2021]

- Walter A, Reynolds A (1986) Fast Neutron Breeder Reactors. Moscow. Energoatomizdat Publ., 623 pp. [in Russian] 